\title{
Identidade docente e educação física: Um estudo de revisão sistemática
}

\author{
Veruska Piresi \& Juarez Vieira do Nascimentoiv \\ Universidade Federal de Santa Catarina, Brasil \\ Gelcemar Oliveira Fariasii \\ Universidade do Estado de Santa Catarina, Brasil \\ Charlene Cristina Martins Suzukiiii \\ Universidade do Vale do Itajaí, Brasil
}

Resumo

O objetivo do estudo foi investigar a produção do conhecimento sobre a identidade docente na Educação Física. A investigação, caracterizada como uma revisão sistemática, ocorreu a partir da busca de estudos nas bases de indexação EBSCO, Scielo, LILACS, Web of Science e ERIC, elegendo os seguintes descritores: identidade (identity), docente (teacher), Educação Física (Physical Education), identidade do professor de Educação Física (Physical Education Teacher's Identity). As evidências apontam que a identidade docente é prioritariamente discutida a partir dos tempos e espaços das histórias de vida para melhor compreender as múltiplas identidades possíveis e encontradas na trajetória profissional. Embora as vivências anteriores à formação inicial tenham sido consideradas, os estudos indicam que é na formação inicial que a identidade realmente se estabelece, especialmente com o aprofundamento das vivências nos estágios. Além disso, a consolidação deste processo emerge no campo profissional; porém, é inacabado e nunca é igual para cada docente.

Palavras-chave

Identidade docente; Estudo de revisão; Educação Física 


\section{Introdução}

A constituição da identidade docente é marcada não só por vivências anteriores ao ingresso no curso de graduação, mas também pela trajetória da carreira do professor (Marcelo, 2009). Na literatura consultada, as investigações que tratam da identidade docente centram-se nos distintos níveis de ensino, desde a educação básica (Dowling, 2006; Gariglio, 2010; Moreira \& Ferreira, 2012; Rodrigues \& Figueiredo, 2011; Rodrigues, Figueiredo, \& Andrade Filho, 2012), o ensino superior (Basei, 2011, 2012; O'Meara \& MacDonald, 2004; Vargas \& Moreira, 2011) e a escola profissionalizante (Gariglio, 2011).

Ao se estabelecer nas constâncias e inconstâncias de rotinas vivenciadas, a identidade profissional pode ser considerada inacabada e não possui uma característica única. Assim, a identidade docente se constitui continuamente na autoanálise de experiências significativas, extraídas da prática e da biografia do professor (Vloet, 2007), a partir das quais é possível identificar os resquícios da formação inicial ao longo da carreira docente, que também evolui com o passar dos anos, na medida em que os professores procuram defini-la para o seu "eu" profissional, influenciados pela escola, reformas educacionais e contextos políticos (Flores \& Viana, 2007).

A base teórica que norteia a maioria dos estudos que procuram compreender a constituição da identidade docente concentra-se em Dubar (1997, 2003, 2005, 2006) e Lopes (2003, 2007). A reflexão sobre o conceito de identidade profissional docente, de acordo com Dubar (1997, 2003), começa a se delinear quando se considera que este conceito é socializado e que a identidade pessoal do indivíduo é mutável e 'inacabada'. No entanto, a partir do contexto profissional e da análise socializada, ela assume caráter coletivo e passa a ser reconhecida como identidade profissional. Desse modo, as identidades são construídas e ganham diferentes significados em tempos e espaços específicos, compondo-se em várias identidades (Dubar, 1997, 2003).

Um aspecto a destacar é que o estudo de revisão sistemática sobre a identidade docente, realizado por Gomes, Ferreira, Pereira, e Batista (2013), analisou o conteúdo de 42 artigos. No entanto, somente três estudos tratavam da identidade docente do professor de Educação Física, são eles: Shehu 
(2009), Oz, Gumus, e Kirimoglu (2011) e Fletcher (2012). Com base nestes resultados, fica evidenciada a necessidade do debate da especificidade da formação de professores de Educação Física sob a ótica da sua constituição identitária.

$\mathrm{Na}$ literatura consultada, os estudos que norteiam as investigações apoiam-se em clássicos da literatura, sendo possível a construção de uma matriz conceitual que representa a base teórica das discussões, e, frequentemente, são citados em publicações na realidade brasileira e internacional. Embora este estudo tenha se originado no cenário nacional, as demandas autorais têm sede na Comunidade Europeia (Quadro 1).

\section{Quadro 1 - Conceitos de base para as reflexões sobre identidade docente na Educação Física}

\begin{tabular}{|c|c|c|}
\hline Autores & Teoria & Cenário \\
\hline $\begin{array}{l}\text { Dubar, C. } \\
(1997,2003 \text {, } \\
2005,2006)\end{array}$ & $\begin{array}{l}\text { A identidade é um produto de comportamentos, características e } \\
\text { atitudes assumidas pelos indivíduos a partir dos papéis } \\
\text { assumidos por eles em diferentes contextos como: a família, } \\
\text { amigos, ou espaços profissionais. A identidade profissional está } \\
\text { ligada, portanto, a um lugar de trabalho, a determinado contexto } \\
\text { social de profissão. É reconhecida como o conjunto de transações } \\
\text { internas ao indivíduo, ou subjetivas, e externas, entre os } \\
\text { indivíduos e as instituições (relacionais). }\end{array}$ & $\begin{array}{l}\text { Reconhecimento de } \\
\text { que a identidade é } \\
\text { fruto de processos de } \\
\text { socialização; o termo } \\
\text { é vinculado a uma } \\
\text { perspectiva } \\
\text { interacionista. }\end{array}$ \\
\hline $\begin{array}{l}\text { Lopes, A. } \\
(2003,2007)\end{array}$ & \multirow{2}{*}{$\begin{array}{l}\text { Identidade docente se configura em: individual, na qual o } \\
\text { professor estabelece suas expectativas, vontades e significados; } \\
\text { coletiva, na qual as possibilidades profissionais são estabelecidas } \\
\text { com fundamento no grupo de pertença. }\end{array}$} & $\begin{array}{l}\text { A psicologia social } \\
\text { norteia as reflexões }\end{array}$ \\
\hline $\begin{array}{l}\text { Lopes et al. } \\
\text { (2004) }\end{array}$ & & $\begin{array}{l}\text { sobre a identidade } \\
\text { docente. }\end{array}$ \\
\hline
\end{tabular}

Uma característica marcante do profissional de Educação Física, a qual interfere na configuração de sua identidade, diz respeito às experiências sociocorporais construídas socialmente no cotidiano dos espaços escolares e não escolares ao longo da vida (Figueiredo, 2010). Além disso, há incidência de mudanças identitárias durante a formação inicial, quando os estudantes tencionam as experiências sociocorporais e os saberes normativos da formação docente. Esta transição se dá nos laços estabelecidos com as escolhas feitas para a entrada e durante a carreira profissional, as quais estão impregnadas por diferentes saberes, agora aplicados e testados (Borges \& Desbiens, 2005). 
As reflexões sobre o uso do corpo e do movimento no processo de identidade docente, especialmente para os professores de Educação Física, ainda são consideradas como componentes didáticos no processo de ensinar. A utilização da 'fala corporal' é um comportamento internalizado pelos docentes como auxílio às ações do ensino (Souza Neto, Benites, \& Silva, 2010). No caso do 'ser professor de Educação Física', as vivências corporais podem produzir rotinas de práticas satisfatórias, que são interiorizadas e se tornam 'práticas não questionadas', sendo utilizadas na resolução de situações imediatas (Sanchotene \& Molina Neto, 2006).

Assim, o presente artigo remete ao interesse de averiguar a produção do conhecimento sobre a identidade docente na Educação Física, por meio da análise dos artigos publicados em periódicos indexados em bases de referência internacionais. Além desse tema ser frequentemente abordado pelas vertentes histórica, pedagógica e legal, também vem sendo estudado com ênfase na discussão ou reorganização da formação de professores pautada pela legislação brasileira em vigor.

\section{Procedimentos metodológicos}

O presente estudo fundamentou-se numa revisão sistemática com base em artigos publicados em periódicos indexados em bases de referência internacionais, que abordam a identidade docente de professores de Educação Física. As revisões sistemáticas promovem o avanço do conhecimento em determinado tema e, ao mesmo tempo, permitem a construção da base teórica das investigações.

A ficha proposta por Kofinas e Saur-Amaral (2008) orientou o processo investigativo, permitindo a construção dos objetivos do estudo, dos critérios de inclusão e de exclusão dos artigos analisados, dos critérios de qualidade e de validade metodológica dos estudos envolvidos, e das fontes de busca, ou seja, possibilitou a definição da busca nas bases de dados escolhidas. Além disso, guiou a coleta dos artigos, realizada por duas pesquisadoras, de modo a garantir a fidedignidade dos critérios e a necessidade do debate para justificar possíveis inclusões ou exclusões das investigações (Quadro 2). 


\section{Quadro 2 - Ficha de pesquisa da revisão sistemática acerca da identidade profissional do professor de Educação Física}

\begin{tabular}{|c|c|}
\hline Conteúdo & Explicação \\
\hline $\begin{array}{l}\text { Objetivo da } \\
\text { pesquisa }\end{array}$ & $\begin{array}{l}\text { Verificar como os estudos publicados em periódicos indexados em bases de referência } \\
\text { internacional vêm discutindo a identidade docente do professor de Educação Física. }\end{array}$ \\
\hline $\begin{array}{l}\text { Equação de } \\
\text { pesquisa a } \\
\text { experimentar }\end{array}$ & Identidade Docente e Educação Física; Physical Education Teacher's Identity. \\
\hline $\begin{array}{l}\text { Âmbito da } \\
\text { pesquisa }\end{array}$ & $\begin{array}{l}\text { A pesquisa será realizada nas bases de dados EBSCO, LILACS, SCIELO, WEB OF } \\
\text { SCIENCE e ERIC, em artigos publicados a partir de 2004, nos campos de procura 'Título' } \\
\text { e 'Assunto'. }\end{array}$ \\
\hline $\begin{array}{l}\text { Critérios de } \\
\text { inclusão }\end{array}$ & $\begin{array}{l}\text { Somente serão considerados artigos publicados em periódicos com classificação de área } \\
\text { na "Educação Física" que apresentem no título ou resumo as equações definidas para a } \\
\text { pesquisa. }\end{array}$ \\
\hline $\begin{array}{l}\text { Critérios de } \\
\text { exclusão }\end{array}$ & $\begin{array}{l}\text { Artigos sem "abstract" e sem texto integral. } \\
\text { Artigos sem acesso online. } \\
\text { Artigos escritos e publicados em outras línguas sem ser português ou inglês. } \\
\text { Artigos que discutam a identidade na área da Educação Física que não atendam o foco da } \\
\text { docência. }\end{array}$ \\
\hline $\begin{array}{l}\text { Critérios de } \\
\text { qualidade e } \\
\text { validade } \\
\text { metodológica }\end{array}$ & $\begin{array}{l}\text { A busca e a definição dos estudos serão feitas por duas pesquisadoras, sendo a ficha de } \\
\text { pesquisa a base para as análises. Resultados "diferentes" deverão ser justificados e } \\
\text { explicados por ambas as investigadoras. } \\
\text { É exigência que os critérios de inclusão sejam criteriosamente respeitados. } \\
\text { As etapas que constituíram os estudos devem ser registradas e definidas com clareza e } \\
\text { coerência. }\end{array}$ \\
\hline
\end{tabular}

O intervalo de tempo considerado para a busca dos estudos compreende os anos entre 2004 e 2014. As mudanças nos marcos regulatórios da formação do profissional de Educação Física passaram a influenciar os estudos realizados sobre a formação de professores e da identidade docente, prioritariamente, na realidade brasileira. A legislação brasileira na área da Educação Física existe desde 2001 e foi movimentada e impulsionada pela normatização dos cursos de bacharelado e licenciatura (Brasil, 2002a, 2002b, 2004), fato que mobilizou a realização de investigações que, de certa maneira, redimensionaram o olhar investigativo sobre a formação profissional em Educação Física. Assim, a motivação da escolha do período supracitado para a busca dos estudos deu-se por entender que a consolidação das investigações foi demarcada nesse período.

Como critérios de inclusão, optou-se por analisar somente os artigos publicados em periódicos escritos em português e em inglês, os que atendiam às equações de pesquisa tanto no título como no resumo, e os que 
estivessem disponibilizados on-line. Já para exclusão, adotou-se o critério de artigos sem abstract, sem texto integral, e artigos sobre a identidade na área da Educação Física que não tratassem da docência em Educação Física.

Após alguns exercícios e ensaios para definir os termos mais indicados para as buscas, foram eleitos os seguintes descritores: identidade (identity), docente (teacher), Educação Física (Physical Education), professor (teacher), identidade do professor de Educação Física (Identity Teacher, Physical Education). Na sequência, definiram-se as bases de dados EBSCO, Scielo, LILACS, Web of Science e ERIC, entendendo que estas bases agregam estudos sobre a temática e área específica de investigação.

A busca nas bases de dados, a partir das equações de pesquisa, utilizando os operadores boleanos and e or, resultou em 170 artigos na EBSCO, 11 artigos na Scielo, 46 na LILACS, 91 na Web of Science e 90 na ERIC. No entanto, com o intuito de reconhecer temas que não atendessem aos critérios e de excluir os estudos duplicados entre as bases de dados, a constituição do grupo de artigos analisados deu-se somente após a leitura dos resumos. Assim, após a revisão dos artigos, foram selecionados 16, sendo 10 publicados em periódicos brasileiros e seis em periódicos internacionais (Quadro 3).

A análise dos dados fundamentou-se em quatro categorias estabelecidas a priori: temática do estudo, objetivos, participantes e principais resultados dos artigos. Estas categorias refletiram o propósito dos trabalhos investigados e permitiram o mapeamento dos temas e suas principais conclusões. No entanto, outras categorias de análise emergiram do contexto geral de todos os artigos e permitiram uma análise mais específica e aprofundada dos principais resultados. Neste processo, foi utilizado o software NVivo 9.2, que analisa dados qualitativos para subsidiar a interlocução dos dados referendados com a fundamentação teórica. Para a organização e análise dos dados, os textos previamente selecionados foram inseridos na íntegra, no software NVivo, foram sistematizados os atributos e abertas as categorias de análise. Não foi necessária a realização de cruzamentos entre atributos e categorias, pois os dados já apresentam consistência para a análise. 


\section{Quadro 3 - Artigos e categorias selecionados para a análise e discussão}

\begin{tabular}{|c|c|c|c|c|}
\hline \multicolumn{2}{|r|}{ Base dados/Autor/ano } & \multirow{2}{*}{$\begin{array}{l}\text { Foco investigativo } \\
\text { Proposta curricular Ensino } \\
\text { Superior }\end{array}$} & \multirow{2}{*}{\begin{tabular}{|l|}
$\begin{array}{c}\text { Procedimento } \\
\text { investigação }\end{array}$ \\
Professores \\
Ensino Superior
\end{tabular}} & \multirow{2}{*}{\begin{tabular}{|c|}
$\begin{array}{c}\text { Tempo da } \\
\text { investigação }\end{array}$ \\
Formação Inicial
\end{tabular}} \\
\hline \multirow{7}{*}{ 엉 } & Basei, A. P. (2012) & & & \\
\hline & Basei, A. P. (2011) & $\begin{array}{l}\text { Proposta curricular } \\
\text { Ensino Superior }\end{array}$ & $\begin{array}{l}\text { Professores } \\
\text { Ensino Superior }\end{array}$ & Formação Inicial \\
\hline & Dowling, F. (2006) & $\begin{array}{l}\text { Reflexão sobre as questões } \\
\text { de gênero na formação inicial }\end{array}$ & $\begin{array}{l}\text { Professores } \\
\text { Educação Básica }\end{array}$ & Formação Inicial \\
\hline & $\begin{array}{l}\text { Vargas, C. P. \& Moreira, } \\
\text { A. F. B. (2011) }\end{array}$ & $\begin{array}{l}\text { Proposta curricular Ensino } \\
\text { Superior }\end{array}$ & $\begin{array}{l}\text { Professores } \\
\text { Ensino Superior }\end{array}$ & Formação Inicial \\
\hline & Tinning, R. (2004) & $\begin{array}{l}\text { Conhecimentos adquiridos na } \\
\text { Formação Inicial }\end{array}$ & Estudo de revisão & Formação Inicial \\
\hline & $\begin{array}{l}\text { O'Meara, J. \& } \\
\text { MacDonald, D. (2004) }\end{array}$ & $\begin{array}{l}\text { Alterações pedagógicas } \\
\text { contexto profissional }\end{array}$ & $\begin{array}{l}\text { Professores } \\
\text { Ensino Superior }\end{array}$ & Formação Inicial \\
\hline & Fletcher, T. (2012) & $\begin{array}{l}\text { Reflexão sobre os estágios } \\
\text { curriculares }\end{array}$ & $\begin{array}{l}\text { Estudantes da } \\
\text { Formação Inicial }\end{array}$ & Formação Inicial \\
\hline \multirow{7}{*}{ ํㅗㅁ } & $\begin{array}{l}\text { Moreira, J. A. \& Ferreira, } \\
\text { A. G. (2012) }\end{array}$ & $\begin{array}{l}\text { Percepção dos estudantes } \\
\text { sobre a constituição da } \\
\text { identidade }\end{array}$ & $\begin{array}{l}\text { Professores } \\
\text { Educação Básica }\end{array}$ & $\begin{array}{l}\text { Inserção nos } \\
\text { espaços } \\
\text { educativos }\end{array}$ \\
\hline & Gariglio, J. Â. (2010) & $\begin{array}{l}\text { Experiências formativas na } \\
\text { Formação Inicial }\end{array}$ & $\begin{array}{l}\text { Professores } \\
\text { Educação Básica }\end{array}$ & Formação Inicial \\
\hline & $\begin{array}{l}\text { Vargas, C. P. \& Moreira, } \\
\text { A. F. B. (2012) }\end{array}$ & $\begin{array}{l}\text { Crise epistemológica da área } \\
\text { da Educação Física }\end{array}$ & Estudo de revisão & $\begin{array}{l}\text { Inserção nos } \\
\text { espaços } \\
\text { educativos } \\
\end{array}$ \\
\hline & $\begin{array}{l}\text { Rodrigues, R. M., } \\
\text { Figueiredo, Z. C., \& } \\
\text { Andrade Filho, N. F. } \\
(2012)\end{array}$ & $\begin{array}{l}\text { A constituição da identidade } \\
\text { a partir das relações } \\
\text { socioprofissionais }\end{array}$ & $\begin{array}{l}\text { Professores } \\
\text { Educação Básica }\end{array}$ & $\begin{array}{l}\text { Inserção nos } \\
\text { espaços } \\
\text { educativos }\end{array}$ \\
\hline & $\begin{array}{l}\text { Rodrigues, R. M. \& } \\
\text { Figueiredo, Z. C. (2011) }\end{array}$ & $\begin{array}{l}\text { A constituição da identidade } \\
\text { a partir da inserção na } \\
\text { Educação Infantil }\end{array}$ & $\begin{array}{l}\text { Professores } \\
\text { Educação Básica }\end{array}$ & $\begin{array}{l}\text { Inserção nos } \\
\text { espaços } \\
\text { educativos } \\
\end{array}$ \\
\hline & $\begin{array}{l}\text { Faria, B. A., Machado, T. } \\
\text { S., \& Bracht, V. (2012) }\end{array}$ & $\begin{array}{l}\text { Reconhecimento social e } \\
\text { identidade docente }\end{array}$ & & $\begin{array}{l}\text { Inserção nos } \\
\text { espaços } \\
\text { educativos } \\
\end{array}$ \\
\hline & $\begin{array}{l}\text { Souza Neto, S., Benites, } \\
\text { L. C., \& Silva, M. F. G. } \\
(2010)\end{array}$ & $\begin{array}{l}\text { Habitus profissionais na } \\
\text { configuração da identidade }\end{array}$ & Estudo de revisão & $\begin{array}{l}\text { Inserção nos } \\
\text { espaços } \\
\text { educativos } \\
\end{array}$ \\
\hline \multirow{2}{*}{$\frac{0}{\frac{U}{\Psi}}$} & Ronspies, S. M. (2011) & $\begin{array}{l}\text { Influências na escolha da } \\
\text { carreira }\end{array}$ & $\begin{array}{l}\text { Estudantes da } \\
\text { Formação Inicial }\end{array}$ & $\begin{array}{l}\text { Anteriores a } \\
\text { formação }\end{array}$ \\
\hline & $\begin{array}{l}\text { Alves, M., Pereira, A., } \\
\text { Graça, A., \& Batista, P. } \\
\text { (2012) }\end{array}$ & $\begin{array}{l}\text { Reflexão estágios } \\
\text { curriculares }\end{array}$ & $\begin{array}{l}\text { Estudantes da } \\
\text { Formação Inicial }\end{array}$ & Formação inicial \\
\hline
\end{tabular}

\section{Resultados e discussão}

A análise pormenorizada dos estudos encontrados apresentou limitações mínimas quanto à organização metodológica, à população investigada e à identificação da base teórica que sustentava a discussão. Pontualmente, os autores apresentaram algumas limitações no que tange ao 
número de envolvidos no estudo (Rodrigues \& Figueiredo, 2011) e ao acesso aos referenciais de base (Vargas \& Moreira, 2012). Essas limitações, porém, não impactaram no processo da análise dos dados.

Assim, as evidências apontadas seguiram as interpretações apresentadas pelos autores sem uma análise crítica do processo. A intenção pautou-se na apresentação fidedigna dos dados durante a busca do relato analítico dos conteúdos e conceitos. A articulação das informações presentes no estudo foi efetivada com base em teorizações postas pela literatura específica das temáticas da identidade docente na área da Educação Física.

\section{Objetivos e procedimentos das investigações sobre identidade docente}

A análise inicial dos artigos investigados revelou a constituição da identidade docente enquanto temática principal em 13 estudos (Alves, Pereira, Graça, \& Batista, 2012; Basei, 2011, 2012; Dowling, 2006; Faria, Machado, \& Bracht, 2012; Fletcher, 2012; Gariglio, 2010; Moreira \& Ferreira, 2012; Rodrigues \& Figueiredo, 2011; Rodrigues et al., 2012; Souza Neto et al., 2010; Tinning, 2004; Vargas \& Moreira, 2011), nos quais a identidade do professor é percebida como um movimento de constituição contínua e mutável, influenciada por premissas internas e externas ao indivíduo, e assume o confronto entre o "eu" e o "outro". Essas características são definidas por Dubar (2005) ao afirmar que as experiências oriundas das histórias de vida de estudantes (identidade para si), as práticas pedagógicas dos docentes do curso de formação inicial (identidade para o "outro") e o desempenho do ofício (identidade visada) podem relacionar-se na constituição da identidade docente.

A constituição da identidade docente foi discutida no espaço e no tempo da formação inicial em seis estudos, os quais procuraram melhor compreender as percepções dos estudantes (Moreira \& Ferreira, 2012), as experiências formativas (Gariglio, 2010), as questões de gênero debatidas nessa fase da formação (Dowling, 2006), o conhecimento adquirido (Tinning, 2004) e os estágios curriculares (Alves et al., 2012; Fletcher, 2012).

O diálogo entre conceitos e vivências reais durante a formação inicial é abordado nos estudos, de modo a entender como se configura o ser 
professor durante a fase de formação acadêmica de sua vida. Ao destacarem a importância dessa fase, Pimenta e Anastasiou (2002) concebem a formação inicial como um momento de incorporação de sentimentos e ações que influenciam o entendimento de ser professor, nomeadamente os valores internalizados pelos professores, o entendimento de como cada um constrói sua história, as posições docentes implicadas pelas visões de mundo, as representações da docência, os saberes, as expectativas e as frustrações.

Nos estudos investigados, a compreensão da constituição identitária do professor é analisada a partir da educação infantil (Rodrigues \& Figueiredo, 2011), das relações socioprofissionais (Rodrigues et al., 2012), do habitus profissional (Souza Neto et al., 2010), do reconhecimento social do professor de Educação Física (Faria et al., 2012) e do ensino superior (Basei, 2011, 2012; Vargas \& Moreira, 2011). Além disso, a identidade docente na área da Educação Física foi relacionada às temáticas sobre a crise epistemológica (Vargas \& Moreira, 2012), às mudanças pedagógicas no contexto profissional (O’Meara \& MacDonald, 2004) e à escolha da carreira (Ronspies, 2011).

No que diz respeito aos objetivos das investigações, ressalta-se que a maioria dos artigos investigados procurou analisar a interferência das propostas de formação inicial na construção da identidade docente. Enquanto Moreira e Ferreira (2012) se concentraram nas percepções do impacto da formação inicial de professores de Educação Física que atuam em escolas públicas e/ou privadas, sobre o impacto da formação inicial em suas situações profissionais, Gariglio (2010) descreveu o papel ocupado pelos componentes disciplinares, pedagógicos e práticos no processo de socialização profissional, e Dowling (2006) abordou o espaço destinado à discussão da construção social de gênero durante o curso de graduação.

Diante das alterações nos marcos regulatórios da formação de professores de Educação Física na realidade australiana, Tinning (2004) concentrou-se nas especificidades da área de saúde na formação inicial. A preocupação do autor foi propor uma discussão sobre o tipo de formação necessária ou desejável aos professores de Educação Física para adotarem uma nova aprendizagem na área da saúde. Na realidade brasileira, a saúde também é discutida na formação inicial em Educação Física por Pasquim (2010), que ressaltou a necessidade de avanços da formação voltada à área 
da saúde nos currículos. Embora reconheça que a saúde compreende um elemento de "dissenso de um currículo conservador" e que ainda não ganhou força nas mudanças curriculares, Pasquim (2010) apresenta a Educação Física enquanto área fértil para a discussão do tema saúde, o que exige necessariamente uma maior capacitação dos profissionais que com ela atuam.

A formação inicial também foi contemplada nos estudos de O'Meara e MacDonald (2004) e de Vargas e Moreira (2011). Enquanto o primeiro abordou as alterações pedagógicas nas estruturas e na organização dos cursos de formação de professores, resultantes de alterações legais, o segundo, além de evidenciar os elementos constituintes da identidade docente, procurou pelos elementos mais relevantes neste momento de formação a partir da perspectiva do professor formador.

Os estágios curriculares foram investigados por Fletcher (2012) e Alves et al. (2012), que analisaram o quanto esse período de formação interfere na percepção do estudante sobre a docência e a formação do "eu professor". Em ambos os estudos, os estudantes estagiários revelaram os resultados das experiências vividas diante de situações reais de prática pedagógica docente, as quais são proporcionadas nesse momento da formação. De fato, o momento dos estágios obrigatórios se configura como tensão entre as identidades biográficas e as identidades relacionais, ou seja, esse é o momento em que o estagiário experimenta a vivência real de seus ideais de ser professor em contato com as necessárias atitudes e habilidades que o próprio campo escolar exige. O impacto dessa experiência proporciona o surgimento de outra identidade, carregada das condições subjetivas do campo de estágio com os saberes oriundos do saber-fazer, ser e sentir do professor (Lopes, 2007). Há ainda os estudos que analisaram a formação inicial a partir da percepção do professor do ensino superior (Basei, 2011, 2012), os quais procuraram compreender como a identidade constituída pelos docentes da graduação interfere em suas escolhas pedagógicas.

Os demais estudos investigados apresentaram uma determinada diversidade de metas investigativas, nomeadamente compreender como as experiências relacionais da professora com os sujeitos adultos e crianças influenciaram na configuração de sua identidade docente (Rodrigues \& Figueiredo, 2011) e refletir sobre a influência das relações socioprofissionais 
na construção da identidade (Rodrigues et al., 2012): ambos os estudos com ênfase na educação infantil. Enquanto compreender as intersubjetividades na cultura escolar e na construção da identidade, com base na teoria de Axel Honneth ${ }^{1}$, foi objetivo do estudo de Faria et al. (2012), Ronspies (2011) investigou um estudante na entrada do curso de graduação, com idade superior a 25 anos, para identificar como os fatores situacionais e sociais vividos por ele interferiram na escolha da carreira e, principalmente, no se sentir professor.

A preocupação de identificar, nos elementos constituintes do habitus profissional de professor, as categorias pedagógicas que possam contribuir para uma possível "gênese" da profissão docente pautada nos saberes, nas práticas e nos valores foi a meta principal do estudo desenvolvido por Souza Neto et al. (2010). Já para Vargas e Moreira (2011), a preocupação foi destacar os desafios a serem superados na autoformação e no reconhecimento profissional para a constituição da identidade do professor de Educação Física.

No que diz respeito aos participantes, cinco estudos envolveram os professores da educação básica, atuantes de diferentes níveis nas esferas municipais, estaduais e federais (Dowling, 2006; Gariglio, 2010; Moreira \& Ferreira, 2012; Rodrigues \& Figueiredo, 2011; Rodrigues et al., 2012). Os professores do ensino superior foram os participantes dos estudos desenvolvidos por O'Meara e MacDonald (2004), Basei $(2011,2012)$ e Vargas e Moreira (2011). As investigações de Ronspies (2011), Fletcher (2012) e Alves et al. (2012) concentraram-se nos estudantes de cursos de formação inicial em Educação Física; e os demais artigos se apresentavam como estudos de revisão sem envolver indivíduos na coleta de dados (Souza Neto et al., 2010; Tinning, 2004; Vargas \& Moreira, 2012).

A análise dos estudos demonstrou que, para se compreender a identidade docente, é necessário investigar o tempo e os espaços da formação deste profissional, cujas marcas são incorporadas e ressignificadas ao longo de toda a sua carreira. Contudo, a trajetória percorrida na profissionalização também registra experiências positivas e negativas que interferem no entendimento dessa identidade. Assim, os artigos se fundamentaram no indivíduo professor, isto é, na análise da constituição da identidade, cuja preocupação era garantir que o docente relatasse suas 
vivências, angústias, crises e satisfações, para compreendê-las como determinantes na sua construção identitária.

\section{Espaço e tempo da constituição da identidade docente em Educação Física}

Ao assumir que a identidade docente se configura nos diferentes tempos e espaços vividos pelos professores, busca-se a compreensão de como as experiências, os contextos e os indivíduos impactam nesta constituição. É no movimento contínuo das múltiplas identidades incorporadas a cada tempo que o professor se faz e refaz na docência. O tempo, de acordo com Patrício (2002), é promotor de criações, porque é nele que se iniciam e se findam as ações, ou seja, "cria quando leva e cria quando traz, cria quando destrói e cria quando constrói" (p. 125), dando sentido às diferentes possibilidades de se sentir professor.

A análise das categorias que reportam aos resultados dos estudos investigados revelou que estes discutem a identidade docente basicamente em três tempos: o trabalho e a construção da identidade nas experiências anteriores à formação (Ronspies, 2011); a identidade no período da formação inicial (Alves et al., 2012; Basei, 2011, 2012; Dowling, 2006; Fletcher, 2012; Gariglio, 2010; O’Meara \& MacDonald, 2004; Tinning, 2004; Vargas \& Moreira, 2011); e a identidade a partir da inserção nos espaços educativos após a conclusão do curso de graduação (Faria et al., 2012; Moreira \& Ferreira, 2012; Rodrigues \& Figueiredo, 2011; Rodrigues et al., 2012; Souza Neto et al., 2010; Vargas \& Moreira, 2012).

Ao abordar os tempos na profissão docente, Patrício (2002) ressalta ainda que "é o presente que cria o passado: dá vida ao passado quando cria o passado. É o futuro que cria o presente: dá morte ao futuro no acto (sic) de dar vida ao presente" (p. 125). Assim, a compreensão dos resultados apontados nos estudos envolvidos permitiu perceber a constância da identidade entre determinados tempos e espaços que, ao se entrelaçarem, reconstituem-se em novas e outras identidades.

\section{O tempo anterior à formação inicial}

A apresentação dos principais resultados dos estudos analisados procurou contemplar as informações a partir da interlocução de cada tempo, 
durante o qual as premissas das múltiplas identidades são percebidas e ressignificadas em um processo contínuo e flexível. Este movimento dá sentido ao processo de construção da identidade que se configura a partir do desempenho do ofício, da prática docente de seus formadores e da prática pedagógica do estudante, ou seja, das experiências trazidas pelas histórias de vida, dos exemplos dos docentes durante a formação inicial e das práticas desenvolvidas em espaços como os estágios obrigatórios e não obrigatórios (Formosinho, 2001).

As experiências anteriores à entrada da formação inicial não podem ser desconsideradas na constituição da identidade docente. Ao discutir a identidade a partir das experiências de vida de um estudante de Educação Física, que tinha como característica peculiar o ingresso no curso após os 25 anos de idade, Ronspies (2011) ressaltou que a formação inicial promoveu uma mudança de valores entre o esporte competitivo e o esporte trabalhado nas escolas diante da experiência marcante no esporte e na atividade física.

As imagens delineadas pelo sentido da docência vão se enraizando desde a experiência como estudante, isto é, antes de se entenderem como professores, os estudantes já assumem uma representação da profissão advinda do período escolar. Estas imagens, ainda iniciais e incipientes, são cruciais para determinar suas atitudes para o ensino tanto positivamente como negativamente. No entanto, tais imagens são elementos concretos e não idealizados como os saberes (Chong, Low, \& Goh, 2011). A imersão na docência, de acordo com Tardif (2000), inicia quando o professor ingressa nos primeiros anos da educação formal, ainda criança, período cujas representações acompanham a trajetória do docente. Nesse sentido, as propostas dos cursos de graduação deveriam romper ou até mesmo abalar estas certezas.

De forma mais específica, a constituição da identidade dos professores de Educação Física está mais atrelada às vivências identitárias oriundas das práticas corporais dos estudantes dos que às relações epistêmicas das escolhas curriculares. Assim, "aprender a nadar, dançar e jogar é mais significativo do que aprender a natação, a dança, o jogo, como conteúdos a serem ensinados nas aulas de Educação Física" (Figueiredo, 2010, p. 157).

Importante destacar que os cursos de licenciatura na área da Educação Física assumem papel fundamental no entendimento do ser 
professor. A partir da definição do currículo, das bases teóricas, do perfil do egresso e dos objetivos do curso é que se configura a identidade do professor estabelecida em cada proposta. Contudo, a incorporação do que é a docência, das competências e das habilidades do professor, assim como da representação do que é ser este profissional, necessita ser percebida individualmente pelos estudantes.

\section{O tempo da formação inicial}

A experiência trazida do tempo da Educação Física escolar para a formação acadêmica incita questionamentos sobre o que ensinar e como ensinar. A quebra do paradigma de ensino embasado no 'saber-fazer' resulta tanto na desvalorização dos conhecimentos da área pedagógica pelos estudantes em formação quanto na valorização dos conhecimentos da área específica, principalmente em relação aos esportes. Embora todo o professor deva ter o domínio do conteúdo específico, há o reconhecimento de que esse conteúdo deve ser aplicado por meio da abordagem pedagógica (Gariglio, 2010).

Os professores entrevistados no estudo de Gariglio (2010) reconheceram a importância da teoria, dos conhecimentos e dos procedimentos acadêmicos, mas criticaram o distanciamento da formação com as questões oriundas da prática. Além disso, os professores afirmaram que o conhecimento serviu de base para os enfrentamentos e dilemas do período de inserção na escola como professores. Nesta perspectiva, nos primeiros anos da docência, é possível identificar um comportamento mais decorrente do papel de estudante no tempo da escola básica do que das aprendizagens dos cursos de magistério e de formação inicial universitária. Esta postura se concretiza em atitudes já vivenciadas e comprovadas como satisfatórias, diferentes das teorias desconectadas do real, estudadas durante a formação (Fortes, 2008).

A falta de conexão entre a teoria e a prática é um problema real nos cursos de formação de professores em Educação Física. A concepção técnica do movimento, historicamente assumida pela área, dificulta a quebra de uma formação enraizada quase que exclusivamente em concepções teóricas, oriundas das ciências biológicas, da esportivização do movimento e do doutrinamento do corpo (Bracht, 1999). 
A marca de uma cultura técnica biológica na formação, em vez de um investimento nos aspectos socioculturais, é discutida no artigo de Dowling (2006), ao tratar dos espaços destinados à reflexão das questões de gênero na formação inicial. O estudo aponta um tema real da escola, que ganha contornos socioeducativos resultantes de posturas sociais, mas que é pouco tratado nos cursos de graduação, o que pode exemplificar o distanciamento do contexto educativo com o contexto formador.

Os relatos extraídos do estudo de Vargas e Moreira (2012) indicam que as vivências dos professores das escolas básicas sustentam os padrões hegemônicos atuais do ensino da Educação Física (competitivo e biológico) que surgiram com a modernidade. Para os autores, a "sua utilização, como forma dominante de prática da Educação Física no contexto escolar, implica reduzir e desvirtuar a função educativa de um professor" (Vargas \& Moreira, 2012, p. 78).

A tensão entre os propósitos da formação e a imersão nos espaços profissionais tem exigido a elaboração de currículos que, além de assumirem o caráter de formação de professores, possam impactar diretamente as práticas docentes. A consequência dessa mudança se concretizará em perspectivas formadoras que apresentem aos estudantes os princípios didático-pedagógicos da docência, as crenças e os valores do ser professor, e que ainda os habilitem para uma atuação crítica e reflexiva (Basei, 2012; Vargas \& Moreira, 2011).

O estudo de O'Meara e MacDonald (2004) analisa como a legislação estimulou a alteração nos estágios e na introdução da pesquisa na formação, reforçando as experiências dos estágios escolares e ampliando a vivência para todos os níveis de ensino. De fato, as mudanças ocorridas na legislação brasileira definiram algumas ações, tais como o desenvolvimento de práticas pedagógicas como componente curricular ao longo do curso e a ampliação da carga horária mínima dos estágios obrigatórios, momento com importante papel na constituição da identidade do ser professor.

As práticas como componente curricular possibilitam a imersão do estudante no ambiente escolar desde as primeiras fases do curso, tornando concretas as situações que no período da formação inicial ainda se configuram como subjetivas. Esta ação estabelece uma articulação intrínseca às disciplinas de estágios supervisionados e às atividades de trabalho 
acadêmico, compondo, assim, a formação da identidade do professor como educador. Ao proporcionarem a incorporação dos papéis da docência, há o reconhecimento da escola e da prática pedagógica nos processos iniciais da formação. Além disso, o contato direto com a escola e com a sala de aula permite que o futuro professor possa realmente compreender as adversidades e as dificuldades da carreira, assim como os benefícios e os encantamentos da profissão. Sobre esse assunto, Fortes (2008) ressalta que "não é no mundo virtual, isto é, na sua formação inicial, mas no mundo da sua atividade real, isto é, na escola em que trabalha, que o professor terá a oportunidade de lidar com o déficit" (p. 85) do cenário educacional.

Os estágios curriculares necessitam ser configurados a partir de princípios norteadores da formação do docente em Educação Física, os quais priorizam a vivência e a internalização de habilidades que promovam sólida formação cultural, científica e técnica. Além de prepararem para conhecer e intervir pedagogicamente no campo das manifestações da cultura do movimento, na escola e em ambientes educacionais, os estágios necessitam conscientizar os estudantes do seu papel de agentes do desenvolvimento humano e social.

Os estudos analisados que se utilizaram dos estágios para discutir a constituição da identidade docente (Alves et al., 2012; Fletcher, 2012; Tinning, 2004) reconhecem este momento como um espaço crucial de vivências e exploração da docência, principalmente por permitir ao estudante elaborar suas primeiras sínteses do que é ser professor. De fato, a configuração das propostas de estágios curriculares, aliada a um referencial epistemológico bem fundamentado, pode se tornar um dos alicerces da transformação de algumas crenças da identidade do professor em transações sociais da identidade que se pensa para um professor. Esta análise torna-se possível, de acordo com Januário (2012), quando se aceita a ideia de que um pensamento didático bem estruturado transcende as crenças, indica coerência com as experiências anteriores e assume uma ação pedagógica mais qualificada.

A implementação dos estágios promove uma tensão comum entre a teoria e a prática na área da Educação Física. A organização das propostas de estágios deve prever e garantir a situacionalidade da formação, ou seja, os contornos reais da experiência profissional se constituem naturalmente, a cada vivência, e vão desenhando os contornos da identidade profissional 
(Batista, Pereira, \& Graça, 2012). Assim, os estágios obrigatórios dos cursos de licenciatura assumem "um espaço de diálogo, de experiência refletida, de construção de identidades profissionais comprometidas com a renovação da Educação Física e com a qualidade da educação" (Batista et al., 2012, p. 105).

Ressalta-se que é nas premissas apontadas pelas experiências vividas nos cursos de formação que o perfil ideal da docência se constitui, assim como concretizam a percepção do estudante para a profissão por ele escolhida. O movimento pensado pelas ações pedagógicas na formação inicial busca traços característicos do que é ser um bom professor, para que este possa atuar com cada vez mais qualificação. Assim, as propostas de formação idealizadas assumem uma nova roupagem para a perspectiva do professor reflexivo. De acordo com Fortes (2008), "não é a prática em si que é formadora, mas a reflexão sobre a prática, a indagação sobre as experiências significativas que permite não apenas constituir-se como autor, mas também aprender consigo mesmo e com os outros" (p. 90).

\section{O tempo de ser professor de Educação Física}

Dentre os estudos que tratam da identidade após a formação inicial, momento em que, oficialmente, o professor ingressa no mercado de trabalho, destaca-se a investigação de Basei (2011), que definiu como principais características de um bom professor de Educação Física a investigação, a ampliação do paradigma técnico instrumental nas aulas, a boa relação com os estudantes e a competência comunicativa. Tais características fazem parte da construção da identidade profissional de base que coloca em jogo as imagens de si e dos outros, a construção do eu ideal e a realização dos seus desejos profissionais.

Ao perpassarem pelos contextos e tempos vividos na carreira dos professores, as características deixam marcas registradas na trajetória profissional, exigindo e estabelecendo mudanças de atitudes, de crenças e de valores da docência. Diferenças no perfil do profissional a cada tempo vivido foram evidenciadas no estudo de Moreira e Ferreira (2012), que afirmam: "nos primeiros anos de serviço há tendências para professores entusiastas, empenhados, criativos ..., com 10 anos de serviço, ainda são entusiastas e 
confiantes, porém mais serenos, reservados e preocupados ..., e depois de 10 anos, ainda são entusiastas, algumas vezes preocupados, mas já cansados e desmotivados" (p. 48).

A constituição da identidade docente ao longo da carreira profissional também foi abordada por Moreira e Ferreira (2012), que concluíram que ela sofre influências das diferentes funções e entendimentos dos momentos vividos. É importante destacar que a identidade já assume uma configuração oriunda da formação inicial e que as mudanças são possíveis e esperadas. Para Fortes (2008), o professor deve ser capaz de, a cada dia, retomar o passado (seus ideais), refazer os vínculos com o presente (o real da coletividade) e reorganizar o futuro numa nova configuração identitária.

Considerando que a constituição da identidade docente é um processo dinâmico, as demandas socioadministrativas do ensino e a afirmação de si se caracterizam por um movimento reflexivo e contínuo da vivência de múltiplas identidades. Assim, as reconstruções e as crises identitárias surgem quando os projetos pessoais não coincidem com as aspirações dos grupos ou das instituições (Bolívar, 2007). Configura-se, portanto, importante para o satisfatório desenvolvimento pessoal e, consequentemente, institucional, a habilidade de articulação entre as exigidas mudanças individuais e a mudança coletiva (Lopes, 2007).

A condição de "segunda classe" no ambiente escolar, muitas vezes imposta aos professores de Educação Física, constitui um elemento fundamental na identidade deste profissional. No entanto, o que tem assegurado as funções desse docente são as dimensões morais e éticas que envolvem seu trabalho, já que o objeto de estudo desse componente curricular promove a imersão aos aspectos sociais, afetivos e culturais (Faria et al., 2012).

A base da significação social da profissão e de suas tradições compreende características marcantes dos professores de Educação Física. A exposição gerada pelo espaço aberto da "sala de aula" deste docente e a expectativa social que a área promove na qualidade de vida dos indivíduos fazem com que a concepção da identidade para si e da identidade para o outro revelem as múltiplas identidades do professor (Rodrigues \& Figueiredo, 2011; Rodrigues et al., 2012; Souza Neto et al., 2010). De fato, o espaço profissional interfere diretamente na constituição da identidade, porque é ele 
que evidencia as múltiplas pertenças dos professores. Além disso, é nas múltiplas experiências que as identidades se organizam e se reorganizam em um movimento contínuo e flexível.

Um aspecto destacado por Dubar $(1997,2003)$ diz respeito ao conceito de identidade profissional docente que começa a se delinear, principalmente, quando se considera que tal conceito é socializado e que a identidade pessoal do indivíduo é mutável e 'inacabada'. Assim, a partir do contexto profissional e da análise socializada, a identidade assume caráter coletivo e passa a ser reconhecida como identidade profissional. O critério base desta mudança é percebido em um processo relacional, em que pares relacionam identidades pessoais de caráter biográfico em um processo de reconstrução e ressignificação de diferentes papéis sociais.

\section{Considerações finais}

A preocupação central do presente estudo foi compreender como o tema da identidade docente na área de Educação Física tem sido abordado nas publicações, o que permitiu concluir que os tempos e os espaços da história de vida de estudantes e de professores são considerados para entender as múltiplas identidades possíveis encontradas em suas trajetórias profissionais. Além disso, a análise pormenorizada da Educação Física indicou que o profissional alcança contornos específicos, já que há características próprias dessa área que singularizam a ação docente.

A maioria dos estudos analisados centra-se no processo de constituição da identidade docente, utilizando, prioritariamente, o tempo da formação inicial e apontando possibilidades para compreensão dos processos identitários. Ressalta-se, ainda, na formação inicial, a interlocução dos currículos formadores, do perfil do egresso e da significação da docência em Educação Física constituída pelo professor e pelo estudante, bem como o movimento entre as identidades biográficas e a identidade visada, que interferem no entendimento do ser professor.

As experiências vivenciadas nas propostas dos estágios curriculares também se apresentam como uma possibilidade significativa para que o estudante se perceba professor e estabeleça um espaço expressivo de configuração da sua identidade de professor. Assim, os estágios são 
considerados momentos de reconstrução de ideais da docência e de concretização de características que serão carregadas ao longo da carreira docente.

Ao abordarem a identidade docente após o ingresso na escola, já como professores habilitados, os estudos demonstraram que o campo educativo, a cultura escolar, as limitações e as dificuldades enfrentadas na prática pedagógica e as relações com os pares e os estudantes são determinantes para a crise de identidades. De fato, a tensão gerada na rotina do ser professor nos diferentes espaços educativos resulta na prospecção de múltiplas identidades, atributo do processo contínuo e mutável da construção das identidades profissionais.

Embora poucos estudos tenham centrado suas análises na influência das experiências de vida ou, mais especificamente, das experiências socioeducativas dos professores antes do ingresso na formação inicial, há o reconhecimento de que estas vivências interferem e são cruciais para o entendimento dos papéis da docência e da elaboração identitária de ser professor.

Os instrumentos frequentemente empregados nos estudos foram as entrevistas e os diários de campo. Ao serem ouvidas as percepções de professores da educação básica e do ensino superior, e serem retratadas as falas de estudantes sobre o ser professor, os estudos qualificaram suas análises no realismo das rotinas dos contextos por eles vividos e transformados.

Em síntese, conclui-se que a identidade docente compreende um tema que permite a diversidade de abordagens, que podem gerar contributos teóricos e auxiliar na reconfiguração de conceitos já estabelecidos. $\mathrm{Na}$ tentativa de elaborar um panorama sobre os estudos da identidade docente na área da Educação Física, o delineamento adotado no presente estudo permitiu identificar conceitos, contrapor entendimentos e relacionar concepções. Diante da complexidade e da relevância da temática investigada, recomenda-se a continuação e a ampliação dos estudos, para que novos questionamentos possam ser identificados e cada vez mais o entendimento do que é ser professor seja o impulso para uma qualificação da docência e da educação. 


\section{Nota}

1 A nova formulação da Teoria Crítica de Axel Honneth tem como pressuposto embrionário o apontamento de "déficits sociológicos" nas formulações anteriores da Teoria Crítica, desde Adorno e Horkheimer até Habermas. Na teoria habermasiana, por exemplo, o principal déficit apontado por Honneth é que a dimensão do conflito social fica em segundo plano, não ressaltando o conflito em torno das violações das pretensões de identidade adquiridas na socialização.

\section{Referências}

Alves, M., Pereira, A., Graça, A., \& Batista, P. (2012). Practicum as a space and time of transformation: Self-narrative of a Physical Education pre-service teacher. USChina Education Review, B7, 665-674.

Basei, A. P. (2011). As ações pedagógicas do professor de Educação Física do ensino superior: Analogias com a trajetória formativa. Acta Scientiarum Education, 33(1), 37-47.

Basei, A. P. (2012). O desenvolvimento profissional e a construção da identidade do professor de Educação Física do ensino superior. Revista Mackenzie de Educação Física e Esporte, 11(1), 44-60.

Batista, P., Pereira, A. L., \& Graça, A. B. S. (2012). A (re)configuração da identidade profissional no espaço formativo do estágio profissional. In J. V. Nascimento \& G. O. Farias (Org.), Construção da identidade profissional em Educação Física: Da formação à intervenção (pp. 81-111). Florianópolis: Editora da UDESC.

Bolívar, A. (2007). Um olhar atual sobre a mudança educativa: Onde situar os esforços de melhoria? In C. Leite \& A. Lopes (Orgs.), Escola, currículo e formação de identidades (pp.13-50). Porto: Edições ASA.

Borges, C., \& Desbiens, J. (2005). Saber, formar e intervir para uma Educação Física em mudança. Campinas: Autores Associados.

Bracht, V. (1999). A constituição das teorias pedagógicas da Educação Física. Cadernos Cedes, 19(48), 69-99.

Brasil (2002a). Resolução n. 1, de 18 de fevereiro de 2002. Diretrizes Curriculares Nacionais dos Cursos de Formação de Professores. Diário Oficial da União, Brasília, 9 abr., Seção 1, p. 31 [Republicada por ter saído com incorreção do original no D.O.U. de 4 mar., Seção 1, p. 8].

Brasil (2002b). Resolução n. 2, de 19 de fevereiro de 2002. Carga Horária dos Cursos de Formação de Professores. Diário Oficial da União, Brasília, 4 mar., Seção 1, p. 9. Oficial da União de 18/1/2002, Seção 1, p. 31.

Brasil (2004). Resolução n. 7, de 31 de março de 2004. Diretrizes Curriculares Nacionais dos Cursos de Graduação em Educação Física. Diário Oficial da União, Brasília, 5 abr., Seção 1, p. 18.

Chong, S., Low, L., \& Goh, K. C. (2011). Emerging professional teacher identity of preservice teachers. Australian Journal of Teacher Education, 36(8), 50-64. 
Dowling, F. (2006). Physical Education teacher educators' professional identities, continuing professional development and the issue of gender equality. Physical Education and Sport Pedagogy, 11(3), 247-263.

Dubar, C. (1997). Para uma teoria sociológica da identidade. In C. Dubar, $A$ socialização: Construção das identidades sociais e profissionais (pp. 103-120). Porto: Porto Editora.

Dubar, C. (2003). Formação, trabalho e identidades profissionais. In R. Canário (Org.), Formação e situações de trabalho (pp. 43-52). Porto: Porto Editora.

Dubar, C. (2005). A socialização: Construção das identidades sociais e profissionais. São Paulo: Martins Fontes.

Dubar, C. (2006). A crise das identidades: A interpretação de uma mutação. Porto: Edições Afrontamento.

Faria, B. A., Machado, T. S., \& Bracht, V. (2012). A inovação e o desinvestimento pedagógico na Educação Física escolar: Uma leitura a partir da teoria do reconhecimento social. Motriz, 18(1), 120-129.

Figueiredo, Z. C. (2010). Experiências profissionais, identidades e formação docente em Educação Física. Revista Portuguesa de Educação, 23(2), 153-171.

Fletcher, T. (2012). Experiences and identities: Pre-service elementary classroom teachers being and becoming teachers of Physical Education. European Physical Education Review, 18(3), 380-395.

Flores, M. A., \& Viana, I. C. (2007). Profissionalismo docente em transição: As identidades dos professores em tempos de mudança. Braga: Centro de Investigação em Educação da Universidade do Minho.

Formosinho, J. (2001). A formação prática dos professores: Da prática docente na instituição de formação à prática pedagógica nas escolas. Revista Portuguesa de Formação de Professores, 1, 37-54.

Fortes, V. M. B. (2008). A constituição da identidade do professor caboverdiano nas relações sociais e de trabalho (Tese de Doutorado). Pontifícia Universidade Católica de São Paulo, São Paulo.

Gariglio, J. A. (2010). O papel da formação inicial no processo de constituição de identidade profissional de professores de Educação Física. Revista Brasileira de Ciências do Esporte, 32(2-4), 11-28.

Gariglio, J. A. (2011). A socialização pré-profissional de professores de Educação Física: A experiência no universo esportivo em questão. Pensar a Prática, 14(2), $1-10$.

Gomes, P. M. S., Ferreira, C. P. P., Pereira, A. L., \& Batista, P. M. F. (2013). A identidade profissional do professor: Um estudo de revisão sistemática. Revista Brasileira de Educação Física e Esporte, 27(2), 247-267.

Januário, C. (2012). O desenvolvimento profissional: A aprendizagem de ser professor e o processo de rotinização das decisões pré-interativas em professores de Educação Física. In J. V. Nascimento \& G. O. Farias (Orgs.), Construção da identidade profissional em Educação Física: Da formação à intervenção (vol. 2, pp. 21-41). Florianópolis: Editora da UDESC. 
Kofinas, A., \& Saur-Amaral, I. (2008). 25 years of knowledge creation processes in Pharmaceutical Contemporary Trends. Comportamento Organizacional e Gestão, 14(2), 257-280.

Lopes, A. (2003). As identidades dos(as) professores(as) portugueses(as) e o lugar da relação nos saberes profissionais. In A. Estrela \& J. Ferreira (Eds.), A formação de professores à luz da investigação - Actas do XII colóquio da Secção Portuguesa da AFIRSE/AIPELF (vol. 1, pp. 37-45). Lisboa: FPCE-UL/AFIRSE.

Lopes, A. (2007). A identidade dos professores portugueses do $1^{\circ} \mathrm{CEB}$ entre o passado e o futuro. In C. Leite \& A. Lopes (Orgs.), Escola, currículo e formação de identidades (pp. 173-192). Porto: Edições ASA.

Lopes, A., Pereira, F., Ferreira, E., Coelho, O., Sousa, C., Silva, M., ...Fragateiro, L. (2004). Estudo exploratório sobre currículo de formação inicial e identidade profissional de docentes do $1^{\circ} \mathrm{CEB}$ : Indícios sobre o papel do envolvimento dos estudantes na gestão do seu currículo de formação. Revista Portuguesa de Educação, 17(1), 63-95.

Marcelo, C. (2009). Desenvolvimento profissional docente: Passado e futuro. Sísifo Revista de Ciências da Educação, 8, 2-22.

Moreira, J. A., \& Ferreira, A. G. (2012). A auto-imagem profissional dos professores de Educação Física em Portugal. Educação \& Realidade, 37(3), 737-759.

O’Meara, J., \& MacDonald, D. (2004). Power, prestige and pedagogic identity: A tale of two programs recontextualizing teacher standards. Asia-Pacific Journal of Teacher Education, 32(2), 111-127.

Oz, A. S., Gumus, S. S., \& Kirimoglu, H. (2011). An investigation of Special and Physical Education pre-service teachers' vocational self-esteem. Journal of Educational Research, 11(45), 107-125.

Pasquim, H. M. (2010). A saúde coletiva nos cursos de graduação em Educação Física. Saúde e Sociedade, 19(1), 193-200.

Patrício, M. F. (2002). Ontem, hoje, amanhã: A unidade criadora do tempo nos ofícios da profissão. Revista Portuguesa de Ciências do Desporto, 2(4), 124-126.

Pimenta, S. G., \& Anastasiou, L. G. C. (2002). Docência no ensino superior. São Paulo: Cortez.

Rodrigues, R. M., \& Figueiredo, Z. C. (2011). Construção identitária da professora de Educação Física em uma instituição de educação infantil. Movimento, 17(4), 65-81.

Rodrigues, R. M., Figueiredo, Z. C., \& Andrade Filho, N. F. (2012). Relações socioprofissionais como elemento de influência na construção das identidades docentes. Movimento, 18(4), 175-195.

Ronspies, S. M. (2011). Who wants to be a Physical Education teacher? A case study of a non-traditional undergraduate student in a Physical Education teacher education program. The Qualitative Report, 16(6), 1669-1687.

Sanchotene, M. U., \& Molina Neto, V. (2006). Habitus profissional, currículo oculto e cultura docente: Perspectivas para a análise da prática pedagógica dos professores de Educação Física. Revista Pensar a Prática, 9(2), 267-280.

Shehu, J. (2009). Professional development experiences of Physical Education teachers in Botswana: Epistemological implications. Teach Development, 13(3), 267-283. 
Souza Neto, S., Benites, L. C., \& Silva, M. F. G. (2010). Da escola de ofício à profissão educação física: A constituição do habitus profissional de professor. Motriz, 16(4), 1033-1044.

Tardif, M. (2000). Saberes profissionais dos professores e conhecimentos universitários. Revista Brasileira de Educação, 13(5), 5-24.

Tinning, R. (2004). Rethinking the preparation of HPE teachers: Ruminations on knowledge, identity, and ways of thinking. Asia-Pacific Journal of Teacher Education, 32(3), 241-253.

Vargas, C. P., \& Moreira, A. F. B. (2011). Identidades em desalinho: Um estudo de campo na formação em Educação Física. Educação Unisinos, 15(3), 214-223.

Vargas, C. P., \& Moreira, A. F. B. (2012). A crise epistemológica na Educação Física: Implicações no trabalho docente. Cadernos de Pesquisa, 42(146), 408-427.

Vloet, K. (2007). Career learning and teachers' professional identity: Narratives in dialogue. Oxford Review of Education, 33(4), 69-84. 
TEACHING IDENTITY AND PHYSICAL EDUCATION: A SYSTEMATIC REVIEW

\begin{abstract}
The aim of this study was to investigate the production of knowledge on the teaching identity in Physical Education. The investigation, characterized as a systematic review, occurred from the search of studies in EBSCO, SciELO, LILACS, Web of Science and ERIC databases, using the following keywords: identity, teacher, Physical Education, Physical Education Teacher's Identity. Evidence suggests that the teaching identity is primarily discussed from times and spaces of life histories to better understand the multiple possible identities found in the professional career. Although experiences prior to the initial training have been considered, studies have shown that identity is, in fact, established in the initial training, especially with deepening of teaching experiences in internships. In addition, the consolidation of this process emerges in the professional field; however, it is unfinished and is never the same for each teacher.
\end{abstract}

Keywords

Teaching identity; Review study; Physical Education

\title{
IDENTIDAD DOCENTE Y EDUCACIÓN FÍSICA: UN ESTUDIO DE REVISIÓN SISTEMÁTICA
}

Resumen

El estudio investigó la producción del conocimiento sobre la identidad docente en la Educación Física. La investigación, caracterizada como una revisión sistemática, ocurrió en la búsqueda de estudios en las bases de indexación EBSCO, Scielo, LILACS, Web of Science y ERIC, eligiendo los descriptores: identidad (identity), docente (teacher), Educación Física (Physical Education), identidad del profesor de Educación Física (Physical Education Teacher's Identity). Las evidencias señalan que la identidad docente es prioritariamente 
discutida en los tiempos y espacios de las historias de vida para comprender las múltiples identidades posibles en la trayectoria profesional. Aunque las vivencias anteriores a la formación inicial hayan sido consideradas, los estudios señalan que es en la formación inicial que realmente se establece la identidad, especialmente con la profundización de las vivencias en las pasantías. Además, la consolidación de este proceso emerge en el campo profesional; sin embargo, es inacabado y nunca es igual para cada docente.

Palabras-clave

Identidad docente; Estudio de revisión; Educación Física

Recebido em setembro/2015

Aceite para publicação em fevereiro/2017

i Núcleo de Pesquisa em Pedagogia do Esporte, Universidade Federal de Santa Catarina, Brasil. ii Grupo de Estudos em Práticas Pedagógicas e Núcleo de Pesquisa em Pedagogia do Esporte, Universidade Federal de Santa Catarina, Brasil.

iii Curso de Educação Física, Universidade do Vale do Itajaí, Brasil.

iv Programa de Pós-graduação em Ciências do Movimento Humano, Núcleo de Pesquisa em Pedagogia do Esporte, Universidade do Estado de Santa Catarina, Brasil.

Toda a correspondência relativa a este artigo deve ser enviada para: Veruska Pires, Avenida Itamaraty, 766, Itacorubi - Florianópolis/SC, Brasil. E-mail: veruskapires03@gmail.com. 